$9(1)(2020) 1-7$
Indonesian Journal of Early Childhood
Education Studies

\title{
Influence of Social/Mass Media as a Change Agent on Childhood Social Pedagogy and Achievement
}

\author{
Semiu Olawale Makinde ${ }^{\bowtie}$
}

DOI: http://dx.doi.org/10.15294/ijeces.v9i1.36259

Al-Hikmah University, Nigeria

\section{History Article \\ Submitted 19 December 2019 Revised 31 April 2020 Accepted 4 June 2020 \\ Keywords \\ Achievement Change Agent Childhood Social Pedagogy Social/Mass Media}

\begin{abstract}
This study investigated the influence of social/mass media as agent of change on childhood social pedagogy and academic achievement in Lagos, Nigeria. Specifically this study examined the impact of social/mass media on early age children social pedagogy and the aftermath effect on their academic achievement in Lagos, Nigeria. The research design was a descriptive type of survey. The sampling technique adopted was purposive and used to sample the population from upper primary school pupils of age 6 to 9 years. This age range can respond to the instrument of the research with free mind. Respondents to the validated questionnaire of reliability index of 0.87 were 490 pupils of 240 boys and 250 girls from ten Nursery and Primary schools in Ifako Ijaiye, Lagos. Three research objectives were raised for the study. Simple percentages and charts were used to represent and analyse the responses from the respondents. The findings show that the social/mass media especially the android phone and television were powerful devices that influence the lives of early age pupils. It teaches them on how to relate with their environment, improve their performance in school and also a means where they cultivate negative attitudes towards people. Conclusively, the media content effect on young pupils depends on the upbringing, because they react to social/mass media differently and are not influenced the same way. Hence, the type of media contents they exposed to should be monitored in other not to be influenced adversely.
\end{abstract}

\section{How to Cite}

Makinde, S. O. (2020). Influence of Social/Mass Media as a Change Agent on Childhood Social Pedagogy and Achievement. Indonesian Journal of Early Childhood Education Studies, 9(1), 1-7.
Correspondence Author:

E-mail: somakinde@alhikmah.edu.ng
p-ISSN 2252-8415

e-ISSN 2476-9584 


\section{INTRODUCTION}

Childhood, this is an early stage of life in human being. The time when a child would start recognizing social media and familiar characters appeal to children from this early age. The fast expansion and development of innovative technology boost children's media through sources like video games, cable $\mathrm{Tv}$. This has greatly promoted the variety and number of such characters. The social and mass media design and develop to promote children awareness, expand their knowledge of the society and the world at large. Creativity, role playing, effective literacy and numeracy, vocabulary and problem solving are part of what the early age pupils can gain from exposure to social/mass media. However, Fadhli and Utami (2018) opine that television being the media that presenting interesting programme $24 / 7$ can be a very sweet honey. But, despite this, television can be a deadly poison if not wisely used because children get entertained and stimulated as they watch television continuously. However, television can be a source of disturbance in their growth and development. The role of parents is very crucial because teachers have little role to play here. There must be limitation on length of watch and type of programmes their children enjoy daily.

Since internet is one of the important tools for social and mass media, both the teachers and pupils need it for effectively use of media. Also, Makinde (2017) posited that internet facilities boost teacher's morale in applying different forms of learning approaches in class like the flipped classroom, blended learning, open and distance learning (ODL), etc. Availability of internet allows students to have access to the content of flipped classroom at home through the flipped classroom package or digital video disk (DVD) player with computer or related gadgets. It encourages equal participation because absent from class or ill-health would not be a barrier for learning, it is easy to meet up with the class through online or offline activities provided in the flipped classroom. This may be difficult to achieved if social and mass media does not exist. In the study of Makinde and Bolaji (2019) it was observed that integrating the internet services in secondary schools will improve the standard of education and encourages critical thinking of the students towards their learning. This may not be possible if children are not been familiar with the nittygritty of the social media tool at their early stage of their learning process.

Furthermore, Makinde (2010) opined that since the use of ICT in various area of speciali- sation is encouraging globally, in the struggle to transform the national educational system, there is urgent need of the internet resources. Through the internet, a lot of materials could be sorted for classroom use as opined by Makinde (2019) that teachers should not trouble much on the production of materials for their classroom, the internet has resources and materials in different form that can be incorporated into their lessons for effective communication to the generality of the class. This in turn reduces the workload and gives room for varieties for pupils with diverse interest and level of assimilation to be active in and out of the vicinity of the classroom since this channel of communication is very friendly.

Pedagogy is at time confused with curriculum, but the later refers to the content of the lesson being taught in the class, while pedagogy simply means the approach, method and technique in how we teach, the practice and theory of educating are all inclusive. Pedagogy is the relationship between culture and learning techniques, and is a factor of educator's belief about how learning should go or take place. Pedagogy needs effective classroom interaction and cordial relationship between the teachers and the learners. The objective is to assist in building on students' prior knowledge, skills and attitude and for teachers to invent a way that will make curriculum relevant to learners, commensurate with their cultures and needs. Pedagogy must take into cognisance of the learning context, how it takes place and with whom. It is the strategy and process adopted towards achieving adequate cognitive learning not about the materials used. Literally, pedagogy stems from the Greek word that means "the art of teaching children". Specifically, Persaud (2019) explained further that agogos means leader in Greek, while teacher refers to pedagogue. The slaves that were charged with the responsibility of taking boys to school and back, tutoring them and teaching them manners were refers to as paidagogos. Pedagogy is of four forms. These include social, culturally responsive, critical and Socratic pedagogies. All involve different approaches of application in teaching styles in the classroom (Persaud, 2017).

The social pedagogy indicates that education is pivotal to a learner's social development and wellbeing, and so must be understood widely as a way to promote a person's growth throughout their entire life. Hence, educational and social questions must see as one, since schooling children are, by nature, social being as we all considered human beings as "social animals". But they require education in order to interact and 
relate adequately as such. Social pedagogy approach can defer from one nation to other based on individual differences in cultural and social traditions. In Nigeria, for example, teachers usually see social pedagogy in the same manner as social responsibility of both the home and the school. In Norway, its emphasis is on working with children and young ones (Persaud, 2019) for instance, social pedagogy could be applied in area of training of young children about compassionate and being generous, using dialogue to dissimilate lessons; studying processes and concepts in the context of modern life; relating common issues within society to our desires and needs to be social being like social exclusion, its consequences and causes. For effective dissimilation and adequate training of children on social pedagogy, social/ mass media has crucial role to play.

Studies reveal that children use media to explore the world, to build contacts with peers, friends and families and to deal with the self (Subrahmanyam \& Šmabel, 2011; Paus-Hasebrink, 2010). Media as agent of change, it offers children orientation and privilege for identification (Paus-Hasebrink, \& Kulterer, 2014), and the internet gives a wide range of opportunities for self-presentation. When browsing the internet, presentation of self needs resources to mediate within the setting, appearance, and also the manners, and the dramatic realization (Skaar, 2009). Social and mass media can have a supporting function in young people's social life and further the development of social understanding (PausHasebrink \& Kulterer, 2014). This indicated that they can offer children stimuli and suggestions for an active engagement with themselves and their environment.

Several researches (Lauricella, et al., 2014; Rideout, et al., 2010) on media and communication have provided opulent empirical justification on young age pupil's use of social media devices and the likes. Most especially, in recent time, many studies have essentially questioned children media utilization within their process of identity construction (Hoffmann, et al., 2017). Marsh, et al. (2005) confirm that in formal education, inserting "popular culture, media and/or new technologies into the communications, language and literacy curriculum have a positive impact on the motivation and engagement of children in learning". Folarin (2012) opined that children behaviour always reflects the aggression or the violence of the characters (dramatics) of the personae they viewed from mass and social media and this also reflected in their dressing.

Social/mass media takes vital position in social life of the young ones and their learning. Attitudes, characters, perception and general behaviour could be cultivated from social and mass media learners exposed to. According to Fadhli and Utami (2018) television as a media presenting interesting program $24 / 7$ can be a very sweet honey but at the same time can be deadly poisonous if not properly monitor by the parents of the young age children. Television as the most favourable media for children who watch it can be entertained and stimulated. Nevertheless, television can be hoo-ha in their growth and development. Parents must play active roles here by giving limitations on the length of time their children can watch television and the type of programs they watch (Fadhli \& Utami, 2018). In quest for effective social life and academic achievement of young children, questions on social and mass media effect on them demands for urgent attention.

The social and mass media programmes aired for children are to boost their social and academic intelligent. Rather, it poses problem of tricks and unnecessary exaggeration, false impression in the heart and minds of the innocent children. Since first impression last longer, it hard for children to make any cogent decisions for themselves on their social life, academics, total wellbeing and future decision because of what they get from social/mass media. This usually, at times, leads them to puzzlement and misery. Thus, this study investigated then reasons why social and mass media justifies children's unfriendly and friendly behaviours towards their friends and people around them at times. Also, looked into the role played by social and mass media on the academic achievements of the children due to their exposure to the media.

The main purpose of this study was to investigate the influence of social/mass media in childhood social pedagogy and academic achievement in Ifako Ijaiye LGA., Lagos, Nigeria. The study specifically was to: Examine if social media influence social pedagogy process of early age children residing in Ifako/Ijaiye, Lagos State. Determine whether early age pupils in Ifako Ijaiye, Lagos enjoy social/mass media they exposed to. Observe if social and mass media exposure influence childhood academic achievement in Ifako/Ijaiye, Lagos state.

\section{METHOD}

The research design was a descriptive type of survey. This allows for the use of questionnaire which was considered as appropriate for this research which aimed at examining the re- 
levance of media effect on childhood social life and academic performance. The population of this study comprises of all nursery and primary school pupils in Ifako Ijaiye area of Lagos, Nigeria. Ten schools were purposively sampled. $\mathrm{Pu}$ pils of age 7- 9 years were randomly selected from each school. 500 pupils were pull up from the ten schools of 50 pupils per school. This age range was chosen because they can be able to read and write and may not be bias in their responses. The instrument used for data collection was a selfstructured questionnaire titled: Social/Mass Media and Childhood Social life and Achievement (SMMCSA). The instrument is of two sections, section $\mathrm{A}$ is for demographic data while section $B$ is of segments of 18 items of option 'YES' or 'NO' to extract facts from pupils on their views on the area of this research.

Senior lecturers from the department of Early childhood education, Kwara State University, Primary education department, University of Ilorin and Science education (Educational technology) department, Alhikmah University, Ilorin validated the questionnaire. Cronbach Alpha statistical from Statistical package for Social Sciences (IBM SPSS) version 21 was used to established the reliability segment by segment thus, reliability coefficients of $\mathrm{r}=0.87$, and $\mathrm{r}=$ 0.84 were obtained at 0.05 level of significance. The researcher and two research assistants gave the instrument to the respondents after taken necessary permission from the schools and the parents through the school heads. After collection and collation, it was discovered that out of 500 questionnaires issued out, only 490 were filled and returned in good condition keeping the rate of return at $98 \%$. Microsoft Excel sheet was used to save and process the data. The research objectives were analysed using descriptive statistics of frequency counts and percentages.

\section{RESULT AND DISCUSSION}

Table 1 illustrates that $240(48.0 \%)$ of the respondents are male (boys) while $250(50.0 \%$ ) are female (girls) that filled and returned the instrument while $3(0.6 \%)$ boys and $7(1.4 \%)$ girls didn't return the instrument. Hence $98 \%$ return rate was discovered. The research also makes sure that gender issue was taken into consideration during sampling exercise as reflected in Table 1 .

Figure 1 indicated that $178(36.3 \%)$ of the respondents were between the ages of 6-7 years, $142(29 \%)$ of the respondents were between $7-8$ years while $170(34.7 \%)$ of the respondents were between the ages of 8-9 years.
Table 1. Social and demographic characteristics of the respondents

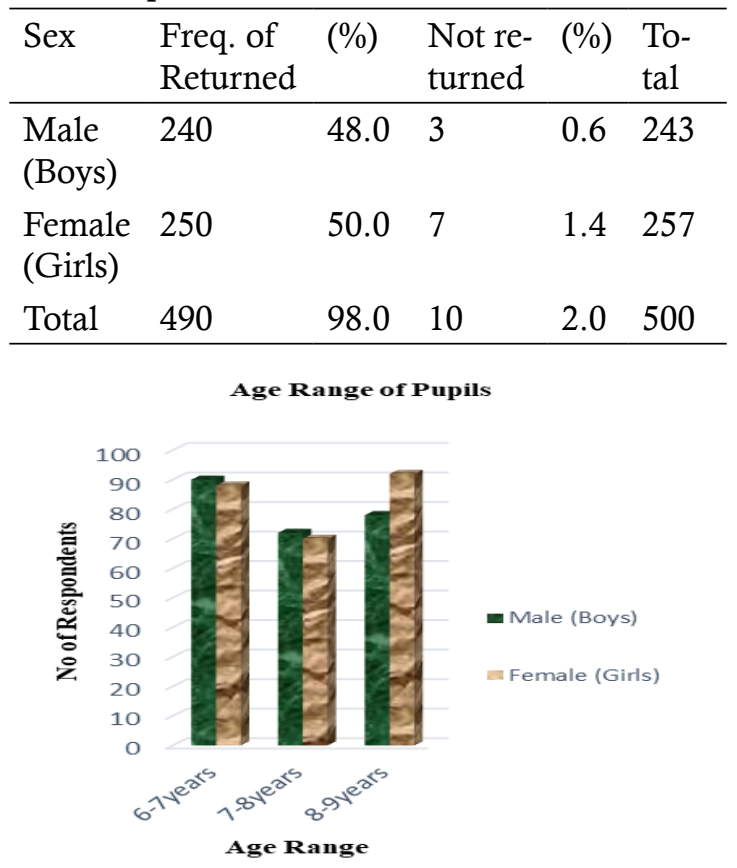

Figure 1. Respondents age range along gender

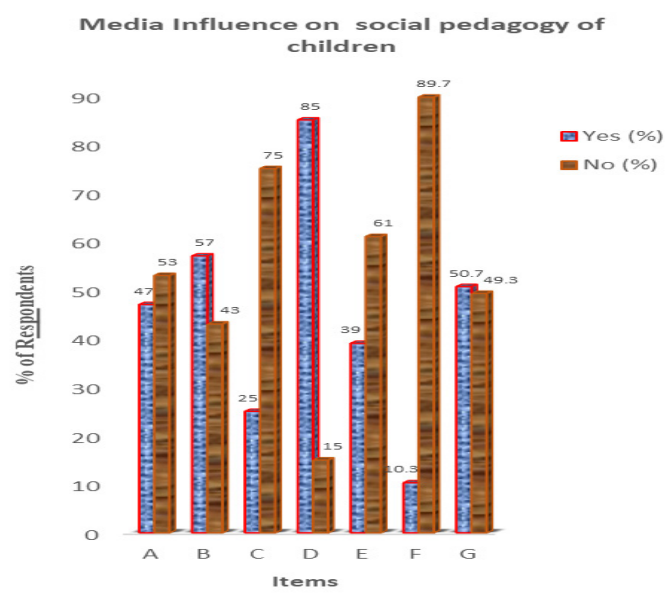

Figure 2. Social/mass media and childhood social pedagogy

Figure 2 revealed that, $47.0 \%$ of the respondents used to watch TV, $25 \%$ listen to radio; YouTube, Facebook, video and so on are watches through the internet as indicated by $57.0 \%$ of the participants. Also, $10.3 \%$ of the respondents picked radio as their best media, $39.0 \%$ of the respondents choose internet and $50.7 \%$ picked Cable $\mathrm{Tv} / \mathrm{Tv}$ as their best. In addition, respondents confirmed that the programme they listen to or watch motivate them to relate well with people. This indicated with $85.0 \%$ of them.

The Figure 3 indicated that the respondents respond to the programmes they watch or 
listen to with $72 \%$ yes. $28 \%$ of them do not respond to the programmes they watch/listen to. $65 \%$ of the respondents confirmed watching and listen to programmes change their ways of doing things both at school and home. Using $50 \%$ as the benchmark, it can be inferred that children responses to the characters they watch/listen to and as a result shows in their conducts both at home and in the school.

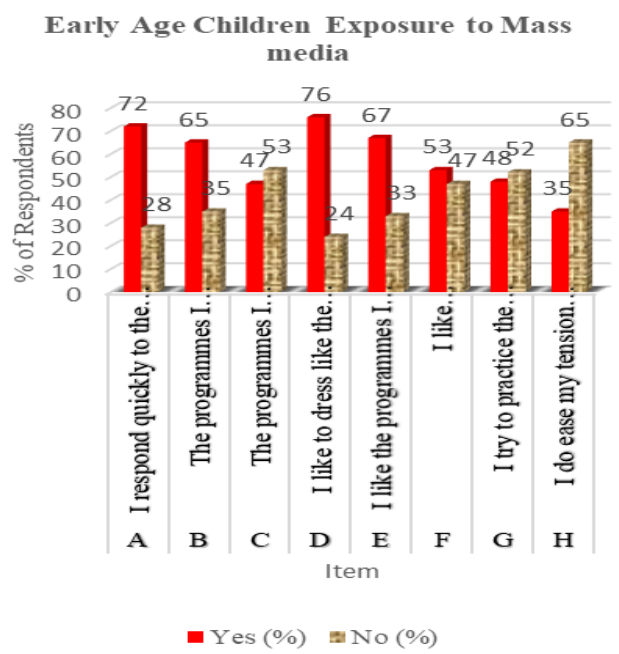

Figure 3. Exposure of children to social and mass media usage

In addition, the figure illustrated that $65 \%$ of the respondents are of the opinion that watching and listening to programmes on social and mass media change the way they relate with their parents and other people while $35 \%$ of the respondents reported no change in the way they interact with their parents and other people. Furthermore, $76 \%$ said that they like to dress like the character they watch while the remaining $23 \%$ of the respondents did not. $67 \%$ of the respondents said they like the programme they listen to or watch while others do not. Also, $53 \%$ of the respondents watch/listen to programmes on violence (action films) while $47 \%$ of the respondents do not. Similarly, out of 260 respondents who watch/listen to programmes on violence, 125 of them practice the violent programmes they watch/listen to while 135 of the respondents do not. Also $35 \%$ of the respondents do ease their tension when they listen to or watch music on radio and TV/Cable TV while $65 \%$ of the respondents do not. Considering $50 \%$ as the benchmark, it can be deduced that social/mass media serve as both good and bad agent of social pedagogy for children because their relationship with people under the influence of bad character they watch/listen to may be adversarial. Also, there may be good influences if they imitate the good once. Although, majority of the children enjoy the programmes they watch or listen to on social/mass media.

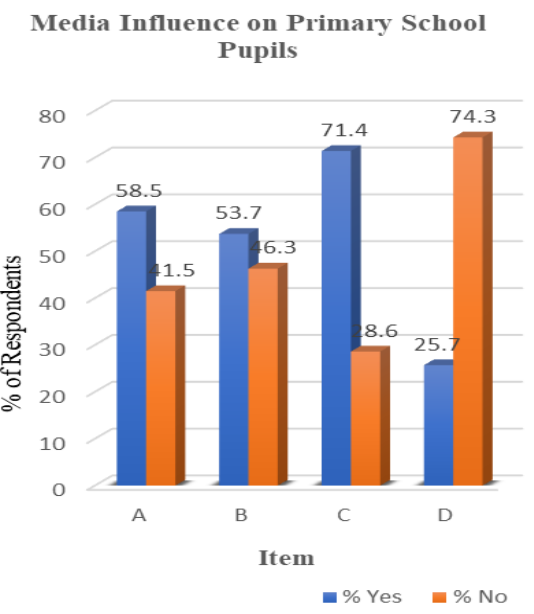

Figure 4. Social/mass media influence on academic achievement of pupils

From Figure 4, 58.5\% of the respondents confirm that the programme they listen to or watch contribute to their knowledge in their studies while $41.5 \%$ said no to this claim. Also, 53.7\% of the respondents use encounter premium and google to search for solution for the given assignment in school while $46.3 \%$ said no to the claim. Furthermore, $71.45 \%$ of the respondents said the social media through internet make study more encouraging and contribute to their studies. However, only $28.6 \%$ of the respondents prepared ahead for class by using encounter premium, flipped classroom or Khan Academy while $74.3 \%$ do not read in preparation for next class through the social media resources mentioned. Considering $50.0 \%$ as benchmark, it was observed that social/ mass media can promote learning because majority of the learners familiar with social/mass media and use them regularly. Although, majority of the learners in primary schools were not familiar with flipped classroom, and Khan Academy as only 126 out of 490 pupils have knowledge.

Influence of social media on social pedagogy process of early age children was examined through the research objective one and the result showed that social/mass media serves as a strong determinant device in the lives of the children social pedagogy, although, its benefits is inexhaustible. This is in supported to the research conducted by Persaud (2019) who established that social pedagogy could be applied in area of training of young children about compassionate and being generous through social media. The result also corroborates the study by Nathanson 
(2014) who stated that young pupils may learn social norms quickly from the television, since 'seeing is believing'. The result also in line with studies by Subrahmanyam and Šmabel (2011) and Paus-Hasebrink (2010) that children use media to explore the universe, to build contacts with friends, peers and families. Also, Paus-Hasebrink and Kulterer (2014) added that social/mass media offers children orientation and privilege for identification.

Regarding the enjoyment early age pupils derived from social/mass media they exposed to. The result showed that children responses to the characters they watch/listen to and as a result shows in their conducts both at home and in the school. The finding is in accord with the findings of Folarin (2012) which opined the children behaviour always reflects the aggression or the violence of the characters (dramatics) of the personae they viewed from mass and social media and this also reflected in their dressing. Also, on the positive influence of social media, it was deduced that there may be good influences if they imitate the good once. Although, majority of the children enjoy the programmes they watch or listen to on social/mass media. In addition, the findings on social/mass media influence on children social life also agreed with the study of Nathanson (2014). Some of the children viewed the influence of the social and mass media as being instructive and educative which helps in widen their horizon of knowledge and enables them to know when they are wrong or right. It was also revealed that children exposure to antisocial contents can leads to destruction but if properly monitored can also help in character model. In addition, it was discovered that the social and mass media enlightened children on how to interact with people although violent attitudes towards people also resulted from the violent movies they watch.

Pertaining to social/mass media usage by early age children, a lot of studies conducted on family communication and media has shown that pupil's action as a whole and media related actions in question, cannot be appreciated satisfactorily without reflecting on families' specific forms of family relation. (Jennings \& Wartella, 2013; Wilson \& Drogos, 2013), which in turn affected by socio-economic backgrounds. This is in support of the earlier findings of Marsh, Brooks, Hughes, Ritchie, Roberts and Wright (2005) which confirm that in formal education, inserting "popular culture, media and/or new technologies into language and literacy curriculum and communication have a positive impact on the motivation and engagement of children in learning".
Conclusively, the findings so far illustrated that the social/mass media have both positive and adversarial effects on children's social pedagogy in Ifako Ijaiye area of Lagos State. Hence, social/mass media could be harmful to pupils although, not all children exposed to it were influenced in the same way. Hence, the following implications can be drawn. The findings of this research have strong implications for the future security of social life and academic development of children. This research contributes to experimental foundation to institute that there would be a great improvement in both social lives and achievement of children if social and mass media are monitored properly for the children's use.

\section{CONCLUSION}

Social and mass media are important tools for social pedagogy and academic performance of children, most especially the early age pupils. In order to control the adverse influence of the social/mass media on children's social pedagogy in Lagos state, media should be encouraged to enlighten the children about the negative effect of media content. The finding from this research, evidenced that effective use of social/mass media will promote children's social pedagogy and improves their academic achievement as evidence in the study of Fadhli and Utami (2018). This research holds strong implications for young children's future security and proper upbringing. The research offers contribution to the experimental foundation to establish that there would be a great improvement in the areas of academic achievement and proper social lives of young children if social/ mass media are tailored properly for the use of children.

\section{REFERENCES}

Fadhli, M. \& Utami, P. S. (2018). The correlation between watching television and bodily-kinaesthetic intelligence of 6 years old children. Indonesian Journal of Early Childhood Education Studies, 7(2), 106-110.

Folarin, B. (2002). Theories of Mass Communication: An Introductory Text, Abeokuta.

Hoffmann, D., Krotz, F., \& Reißmann, W. (2017). Mediatisierung und Mediensozialisation: Problemstellung und Einführung. In Mediatisierung und Mediensozialisation (pp. 3-18). Springer VS, Wiesbaden.

Jennings, N. A., \& Wartella, E. A. (2013). Digital technology and families. The Routledge Handbook of Family Communication, 448-462.

Lauricella, A. R., Cingel, D. P., Blackwell, C., War- 
tella, E., \& Conway, A. (2014). The mobile generation: Youth and adolescent ownership and use of new media. Communication Research Reports, 31(4), 357-364.

Makinde, S. O. \& Bolaji, H. O. (2019). Appraisal of Internet Services Usage by Secondary School Teachers for Professional Development in Lagos, Nigeria. International Journal of Indonesian Education and Teaching, 3(2), 138-148.

Makinde, S. O. (2010). Effect of availability and level of use of internet services on professional development of academic staff in tertiary educational institutions in Lagos state, Nigeria. Unpublished Master degree (M. Ed.) Thesis, Science \& Technology Education Department, University of Lagos, 2.

Makinde, S. O. (2017). Effects of A Developed Flipped Classroom Package on Senior Secondary School Students' Performance in Mathematics in Lagos, Nigeria. Unpublished Ph. D. Thesis, University of Ilorin, Ilorin, Nigeria, 86-90.

Makinde, S. O. (2019). The Flipped Classroom: A Twirl on Pedagogy. International Journal of Research and Scientific Innovation. 6(5), 130-134.

Marsh, J., Brooks, G., Hughes, J., Ritchie, L., Roberts, S., \& Wright, K. (2005). Digital beginnings: Young children's use of popular culture, media and new technologies. Report of the 'Young Children's Use of Popular Culture, Media and New Technologies' study, funded by BBC Worldwide and the Esmée Fairbairn Foundation. Sheffield, UK: Literacy Research Centre of the
University of Sheffield, BBC Worldwide and Esmée Fairbairn.

Nathanson, A. I. (2004). Factual and Evaluative Approaches to Modifying Children's Responses to Violent Television 1. Journal of Communication, 54(2), 321-336.

Paus-Hasebrink, I. (2010). Das Social Web im Kontext der Entwicklungsaufgaben junger Menschen. Medien Journal, 34(4), 20-34.

Paus-Hasebrink, I., \& Kulterer, J. (2014). Praxeologische Mediensozialisations forschung. Langzeitstudie zu sozial benachteiligten Heranwachsenden [Praxeological media socialisation research: A longitudinal study regarding socially disadvantaged adolescents] Assisted by P. Sinner. BadenBaden, Germany: Nomos.

Persaud, C. (2019). Pedagogy: What Educators Need to Know. Uploaded March 1, 2019. Retrieved 15 December 2019 from https://tophat.com/ blog/pedagogy/

Skaar, H. (2009). Branded selves: How children in Norway relate to marketing on a social network site. Journal of Children and Media, 3(3), 249-267.

Subrahmanyam, K., \& Smahel, D. (2010). Digital youth: The role of media in development. Springer Science \& Business Media.

Wilson, B. J., \& Drogos, K. L. (2013). The mass media and family communication. In A. Vangelisti (Ed.), The handbook of family communication (2nd ed., pp. 424-447). Mahwah, NJ: Lawrence Erlbaum Associates. 